\title{
Market Power and Generation from Renewables: The Case of Wind in the South Australian Electricity Market
}

Australian Economic Report: No. 2

Bruce Mountain

Centre for Strategic Economic Studies Victoria University Melbourne June 2012 
The Australian Economic Report is an occasional series of research-based analyses of important issues facing the Australian economy, produced by researchers from the Centre for Strategic Economic Studies, Victoria University, Melbourne.

Bruce Mountain is Director, Carbon and Energy Markets, and Researcher, Centre for Strategic Economics Studies, Victoria University.

(C)2012

Centre for Strategic Economic Studies Victoria University

PO Box 14428

Melbourne VIC 8001

Telephone: 0399191340

Fax: 0399191350

Contact: bruce.mountain@carbonmarkets.com.au 


\section{Table of Contents}

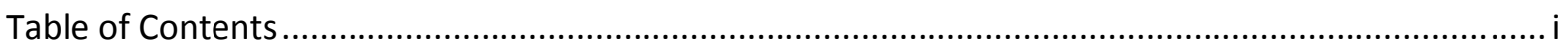

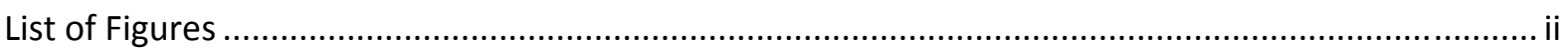

Abstract iii

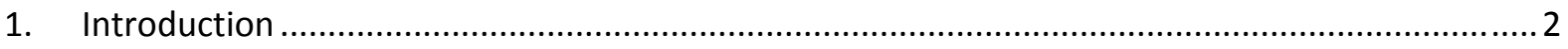

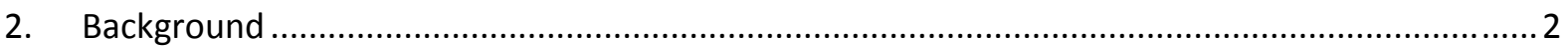

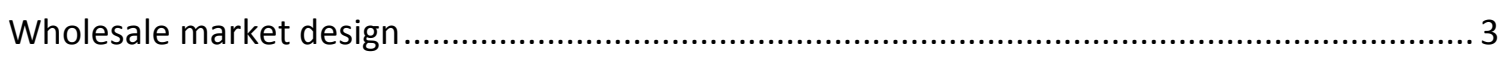

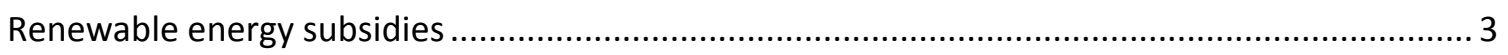

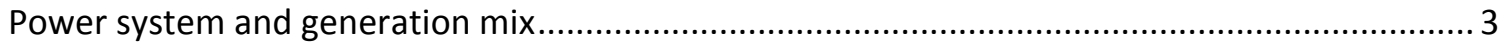

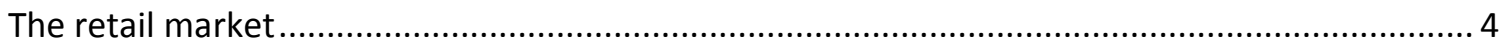

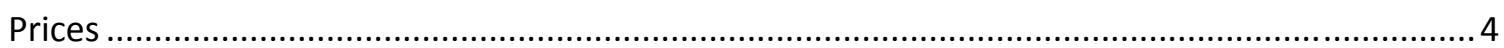

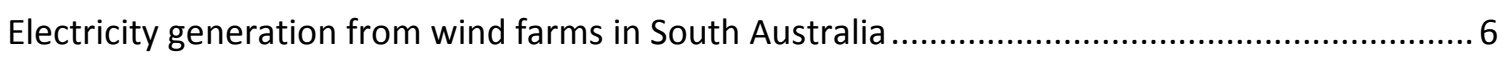

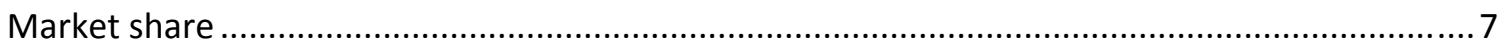

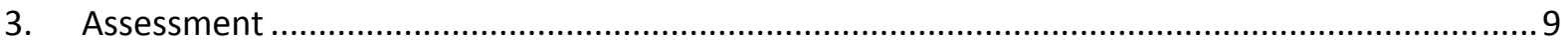

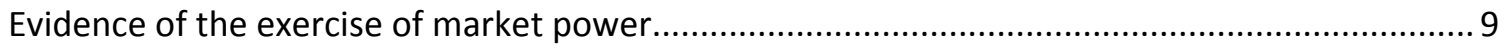

Impact of the exercise of market power on the average spot prices received ............................ 12

Impact of the exercise of market power on generator revenues and profits .............................. 12

Impact of wind farms on electricity prices in South Australia .................................................. 15

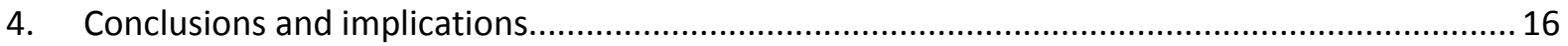

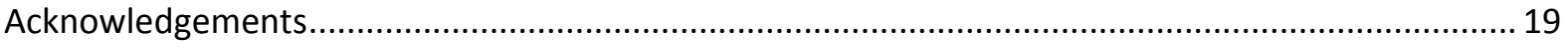

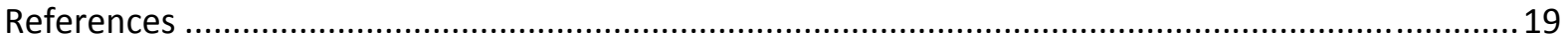




\section{List of Figures}

Figure 1. Price duration curves for the highest priced 72 settlement periods

Figure 2. Supply-weighted average annual prices including and excluding the 72 highest price settlement periods

Figure 3. Demand and residual demand duration curves for South Australia in 2011 ........................ 6

Figure 4. Energy market share (TWh) of wind, fossil fuel generation and net import .......................... 7

Figure 5. Market share during the 72 highest price settlement periods ........................................... 8

Figure 6. Duration curves of demand and residual demand for the 72 highest price settlement periods in 2011

Figure 7. The impact of the highest priced 72 settlement periods on the prices achieved by wind generators

Figure 8. Average capacity factors of different generation technologies during the highest 72 settlement periods

Figure 9. Average prices achieved in the spot market for different generating technologies from 2008 to 2010

Figure 10. Spot market revenue recovered in the 72 highest price settlement periods in 2008 as a percentage of total 2008 spot market revenue

Figure 11. Return on investment for new entry CCGT, GT and wind farms based on outcomes in 2008, including and excluding revenues from the highest priced 72 settlement periods.... 14 


\begin{abstract}
This paper examines whether outcomes in the electricity market in South Australia are consistent with theoretical analysis and market modelling that concluded that intermittent generation benefits less from market power than conventional generation. The paper finds that, based on actual outcomes in South Australia over the period from 2006 to 2011, the exercise of market power is likely to result in a preference for investment in conventional fossil fuel based electricity generation, relative to investment in wind farms. It also concludes that while wind farms have taken market share from conventional generators, wind farms are not likely to have reduced spot prices in South Australia to the extent that seems apparent in electricity markets in other countries where wind farms are as prevalent but market power is less significant. The implication of these conclusions is that higher subsidies will be needed to ensure that the Australian Government's renewable electricity targets will be met, than would be the case if the exercise of market power did not have these distributional effects. The paper suggests consideration of changes to market design and competition law to remedy this.
\end{abstract}

Key words: Wind farms, market power, electricity market design 


\section{Introduction}

In a theoretical analysis of wind power and market power in competitive electricity markets, Twomey and Neuhoff (2009) concluded that a limited amount of market power is unavoidable and is sometimes perceived as acceptable as it creates revenues for generators to recover some of their fixed costs. They noted that it is generally assumed that market participants benefit equally from the increased prices, but concluded that this assumption is not satisfied if different production technologies are used.

They then assessed the case of a mix of conventional generation and intermittent generation. They concluded that intermittent generation benefits less from market power than conventional generation and that allowing some level of market power as a means of encouraging investment in new generation may result in a bias against intermittent technologies. Finally they concluded that market power monitoring focussed on retaining prices paid by consumers below a certain level is likely to ignore the distortions market power can still create between different technologies.

Green and Vasilakos (2010) modelled the interaction of market power and wind power in the British power system, assuming that by 2020 one-third of electricity generation would be from renewable sources and most of this from wind farms. They agreed with the direction of Twomey and Neuhoff's conclusions but noted that while wind generators gain less than conventional generators from the exercise of market power, the differential ( $15 \%$ for on-shore wind and $17 \%$ for off-shore wind) was much less significant when compared to the impact of market power on wholesale prices (more than doubling them).

This paper examines the extent to which Twomey and Neuhoff's theoretical analysis and Green and Vasilakos' market modelling is reflected in actual outcomes in South Australia over the period from 2006 to 2011.

The paper begins by setting the background to the power market in South Australia. It then analyses data on prices, demand and production to develop observations on the exercise of market power and the impact of this on prices, generator revenues and profits. This establishes the grounds for the main conclusion of this paper: that the exercise of market power in South Australia results in a bias against investment in wind farms. The paper finally addresses, in a preliminary way, the issues this raises for policy in view of the Government's objective of rapidly expanding renewable generation.

\section{Background}

At the end of 2011, 1,900 MW of wind capacity was operating in Australia. Of this, 1,200 MW was installed in South Australia. In 2011 wind generation accounted for $2.9 \%$ of the electricity transacted in the NEM, but in South Australia $26.7 \%$ of the electricity transacted in the National Electricity Market (NEM) and produced in South Australia, came from wind farms. 


\section{Wholesale market design}

The electricity market in South Australia is the second smallest of the five regional electricity markets in Australia's south and eastern states that together form the NEM. The NEM is a mandatory spot market for generators larger than $30 \mathrm{MW}$. It is centrally dispatched and settled through the Australian Energy Market Operator. Spot prices are calculated for 5-minute dispatch periods and settled half-hourly based on the average price of the six dispatch periods in each half hour. The price in each dispatch period in South Australia is based on the marginal change in production costs needed to meet the last MW of demand supplied to Adelaide, the state capital.

The main spot market has a maximum price cap of $\$ 12,500 / \mathrm{MWh}$ and a minimum floor price of $\$ 1,000 \mathrm{MWh}$. There is also a Cumulative Price Threshold that caps prices at $\$ 300 / \mathrm{MWh}$ if the rolling seven-day sum of half-hourly spot prices exceeds $\$ 187,500$. In addition to the mandatory spot market, there are exchange-based futures and over-the-counter forward contract markets that allow producers, retailers and consumers to hedge their exposure to spot prices. The South Australia contract market is however illiquid (Australian Energy Regulator 2009).

Generators have non-firm transmission access (they are not compensated if they are constrained off the power system as a result of transmission congestion). Generators pay for marginal transmission losses (calculated at their points of connection) but do not pay for the use of the shared transmission system.

\section{Renewable energy subsidies}

Australia has a mandatory renewable energy certificate subsidy scheme. Wind farms (and various other renewable electricity technologies) connected to the main transmission and distribution system receive one certificate (known as the Large Scale Generation Certificate - LGC) per MWh produced, until 2030. Electricity retailers are obliged to surrender to the Government a number of these certificates each year in proportion to the electricity they sell. The price of these certificatescurrently around AUD40 per certificate is determined in a market but failure to surrender permits results in non-deductible penalty of $\$ 65$ per certificate shortfall. The annual permit surrender obligation is rising rapidly to stimulate investment in renewable generation. The Australian Government suggests that $10,071 \mathrm{MW}$ of wind generation will be operational by 2020 (compared to $1,900 \mathrm{MW}$ that was operational at the end of 2011) (Climate Change Authority 2012).

\section{Power system and generation mix}

The South Australian power system has significant inter-annual demand variation. Minimum annual demand is around $1000 \mathrm{MW}$, the peak demand is around 3,300 MW and average annual demand is around 1,500 MW - about half peak demand. The South Australia power system is connected to the Victorian power system through two separate interconnectors that together have sufficient interconnector capacity to meet around a third of the average demand in South Australia (or a sixth of the peak demand). 
Electricity production in South Australia is dominated by conventional fossil fuel plant. There is 780 MW of brown coal generation from units that were commissioned between 1967 and 1985. This is currently the lowest variable cost production. There is also 1,280 MW of gas steam-cycle (thermal) generation capacity that was commissioned between 1967 and 1977, $663 \mathrm{MW}$ of Combined Cycle Gas Turbine (CCGT) capacity commissioned in 2000 and around 729 MW of Open Cycle Gas Turbine (OCGT) plant, the last of which was commissioned in 2002, although there have been some minor additions since then.

\section{The retail market}

The South Australian electricity retail market is dominated by one retailer that serves around $60 \%$ of small customers, with the remaining $40 \%$ of small customers split roughly equally between another two retailers. There is also a number of small retailers who have an inconsequential customer base (Australian Energy Regulator 2011). Each of the three main retailers is understood to also own and/or control enough generation to meet their South Australian demand..

\section{Prices}

For most of the year (typically more than $99.95 \%$ of all settlement periods in a year), it would appear that the spot market in South Australia is competitive. Prices seem to be based on bids that reflect marginal production costs, and are predictable.

However, the spot prices in a few settlement periods in the period from 2008 to 2010 - have risen 60 to 70 times higher than a reasonable estimate of the highest marginal operating costs of dispatched plant. Price duration curves from 2008 to 2011 for the 72 highest price settlement periods in each year (corresponding to just $0.4 \%$ of the year) are shown in Figure 1 below Seventy two settlement periods were chosen since extremely high prices do not typically occur for longer in any one year.

Figure 1. Price duration curves for the highest priced 72 settlement periods

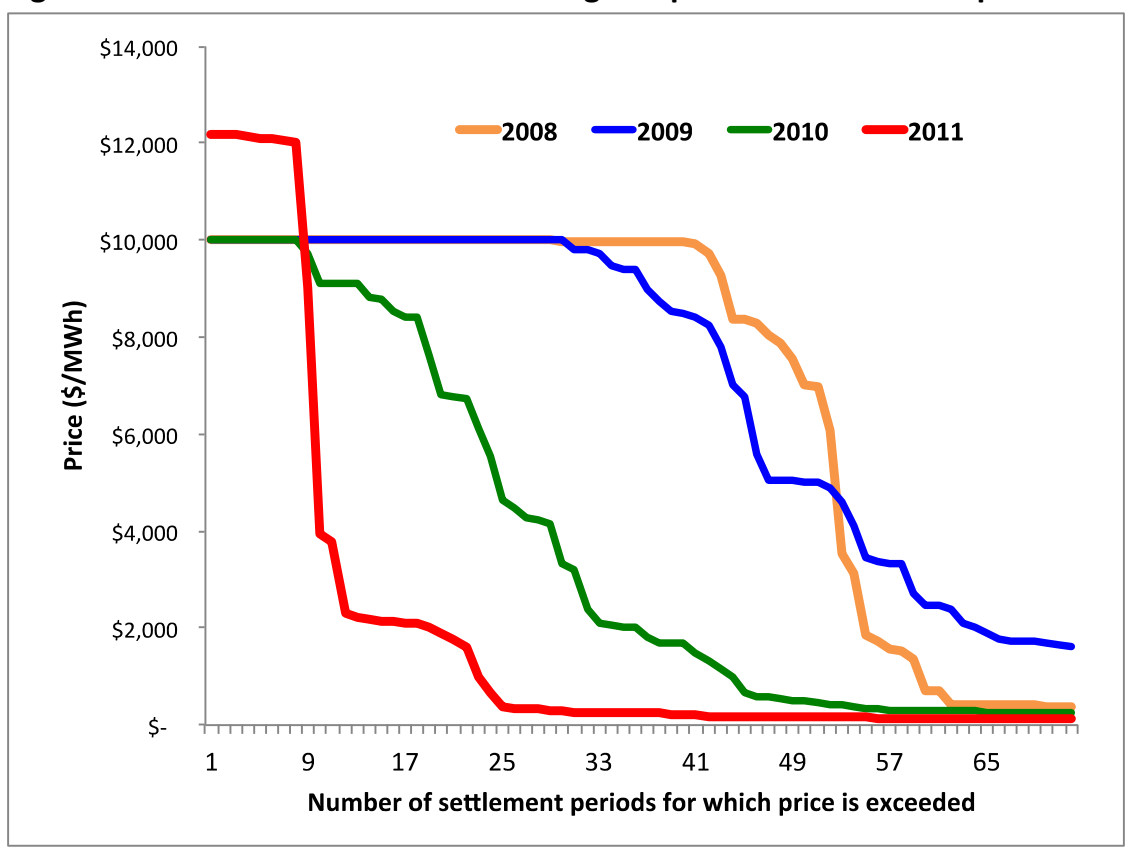


The extreme price settlement periods have a significant impact on average annual prices. This is shown in Figure 2, which compares the supply-weighted average annual price including and then excluding the 72 highest price settlement periods. The figure shows that in 2008 and 2009 in particular the average annual spot price more than $130 \%$ higher than they otherwise would have been if the 72 highest price settlement periods were excluded. The effect is still evident although to lesser extent in 2010 and 2011. On average over the period from 2006 to 2011, the prices in the 72 highest price settlement periods in each year raised the average annual spot prices by $77 \%$, as shown in Figure 2.

The higher prices in 2011 (compared to previous years) reflect the increase in the Market Price Cap to $\$ 12,500 / \mathrm{MWh}$ in that year.

Figure 2. Supply-weighted average annual prices including and excluding the $\mathbf{7 2}$ highest price settlement periods

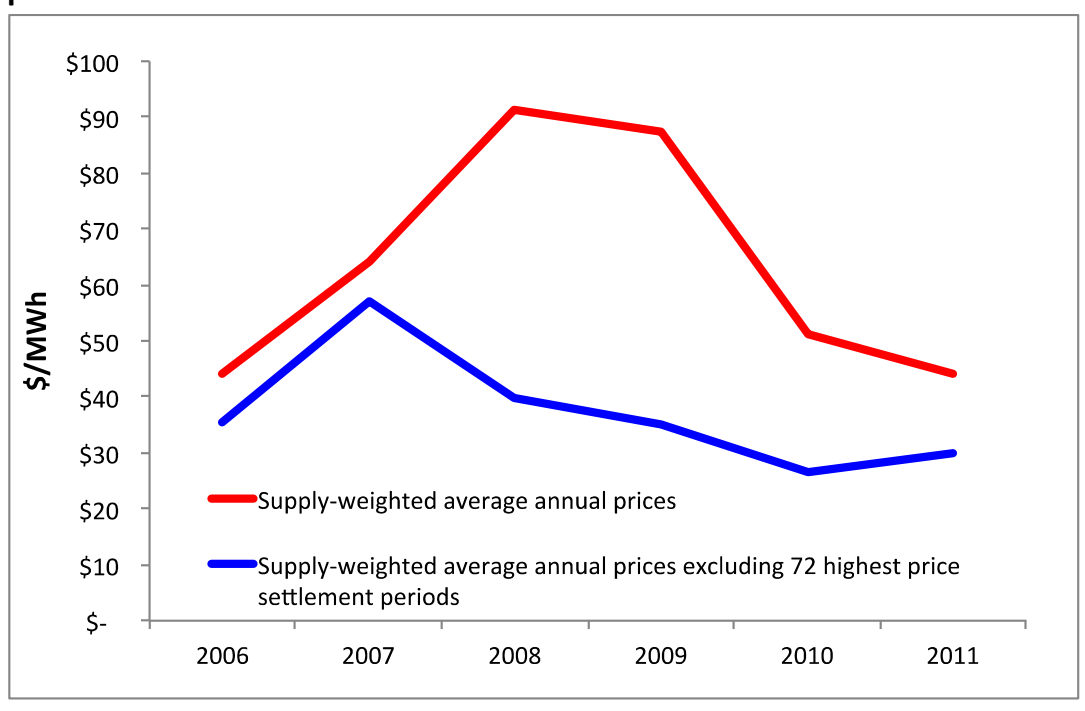

This level of extreme prices is not evident in electricity markets in other countries. Whereas in South Australia the price in the top 8 hours in 2010 raised average spot prices by $22 \%$, in Great Britain, the average of the system sell and system buy prices for the top 8 hours only raised average annual sell and buy prices by $0.6 \%$ and $0.7 \%$ respectively (Carstairs and Pope 2011). In Germany for the period October 2009 to November 2009, spot prices spiked at Euros500/MWh for just one hour and were only above Euros200/MWh for another five hours (Nicolisi 2010). By comparison in South Australia over the same time period, prices peaked at $\$ 10,000 / \mathrm{MWh}$ and averaged more than $\$ 3,700 / \mathrm{MWh}$ for 26 hours. In the United States of America in 2011 the highest prices in its electricity markets were NEPOOL (\$151/MWh), PJM West (\$143/MWh), California (SP15-EZ) $(\$ 57 / M W h)$, Texas (ERCOT) $\$ 610 / M W h$ (Energy Information Administration 2012). In New Zealand in the year to June 2008 (a year of very volatile prices), the maximum price at any node was $\$ 1106 / \mathrm{MWh}$ and was only above $\$ 600 / M W h$ for two hours (New Zealand Electricity Authority 2012). By comparison in South Australia in 2008 prices were above $\$ 1000 / M W h$ for 29 hours. 
The exceptionally high prices in South Australia have also been seen in other regions (Victoria, New South Wales, Queensland and Tasmania) of the National Electricity Market, although they have generally persisted for shorted periods. While the impact of prices in the top 72 settlement periods is South Australia has been exceptional, in these other NEM regions the impact has not been trivial. In Victoria, New South Wales and Queensland, average annual prices were on average than $30 \%$ higher over the period 2007 to 2011 as a result of the prices in the top 72 settlement periods. To be clear we are not suggesting that the existence of extremely high spot prices in Australia is evidence of the exercise of market power. We examine the issue of market power in South Australia in more detail later.

\section{Electricity generation from wind farms in South Australia}

Wind generation has grown, particularly since 2004 , to $26.7 \%$ of the electricity produced in South Australia that is transacted through the NEM. There are currently 15 on-shore wind farms in South Australia with an average size of $80 \mathrm{MW}$, and all are located reasonably close to the main load centre in Adelaide.

Independent power producers have developed approximately three quarters of the wind farm capacity. Typically production is sold through 10-20 year contracts to the three dominant retailers. These retailers (who also typically own and operate significant amounts if generation) are becoming dominant wind farm developers and in some cases have sold wind farms that they have recently developed, to infrastructure companies and passive investors. There is around 2,400 MW of additional wind generation capacity in South Australia in various stages of development, although none of this is currently under construction (Australian Energy Market Operator 2011).

Wind generation has had a reasonably significant impact on residual demand (metered simultaneous demand less wind generation) as shown in Figure 3, particularly during low demand periods.

Figure 3. Demand and residual demand duration curves for South Australia in 2011

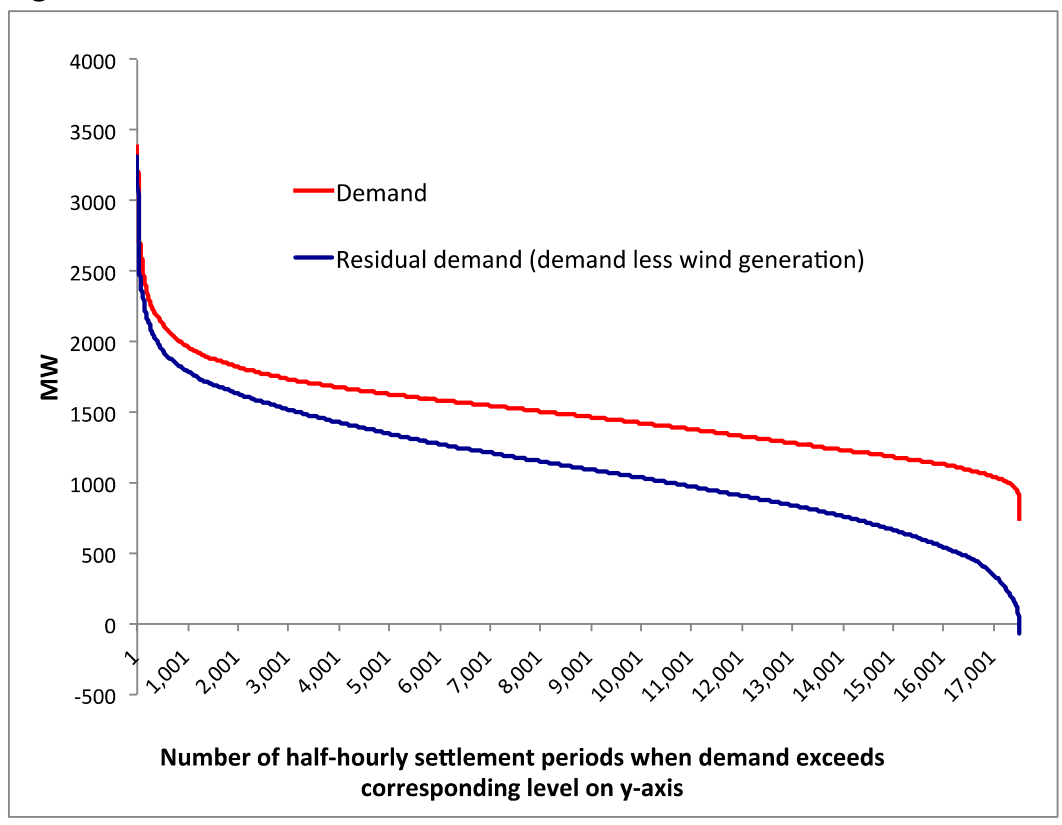


Despite its significant market penetration, wind generation in South Australia does not yet appear to have had a significant impact on power system stability. For example, the maximum half-hourly decrease in wind generation in 2011 was $217 \mathrm{MW}$, while the maximum half-hourly increase in demand was $257 \mathrm{MW}$. The maximum half-hourly increase in residual demand (demand less wind generation) was $299 \mathrm{MW}$, not significantly higher than the maximum variability of wind generation. The average half-hourly change in residual demand was $53 \mathrm{MW}$ with a standard deviation of $45 \mathrm{MW}$, not significantly higher than the average half-hourly change in demand of $41 \mathrm{MW}$ and standard deviation of $38 \mathrm{MW}$. This supports the conclusion in (Simshauser 2011) that the impact of wind generation on the costs of operating the power system through the procurement of various forms of operating and contingent reserves have so far been negligible.

\section{Market share}

From 2005 to 2011 average demand in South Australia was approximately constant while peak demand increased by $29 \%$. With approximately unchanged average demand, rising wind generation (and to a lesser extent higher imports) have gradually displaced South Australiam fossil fuel electricity production as shown in Figure 4.

Figure 4. Energy market share (TWh) of wind, fossil fuel generation and net import

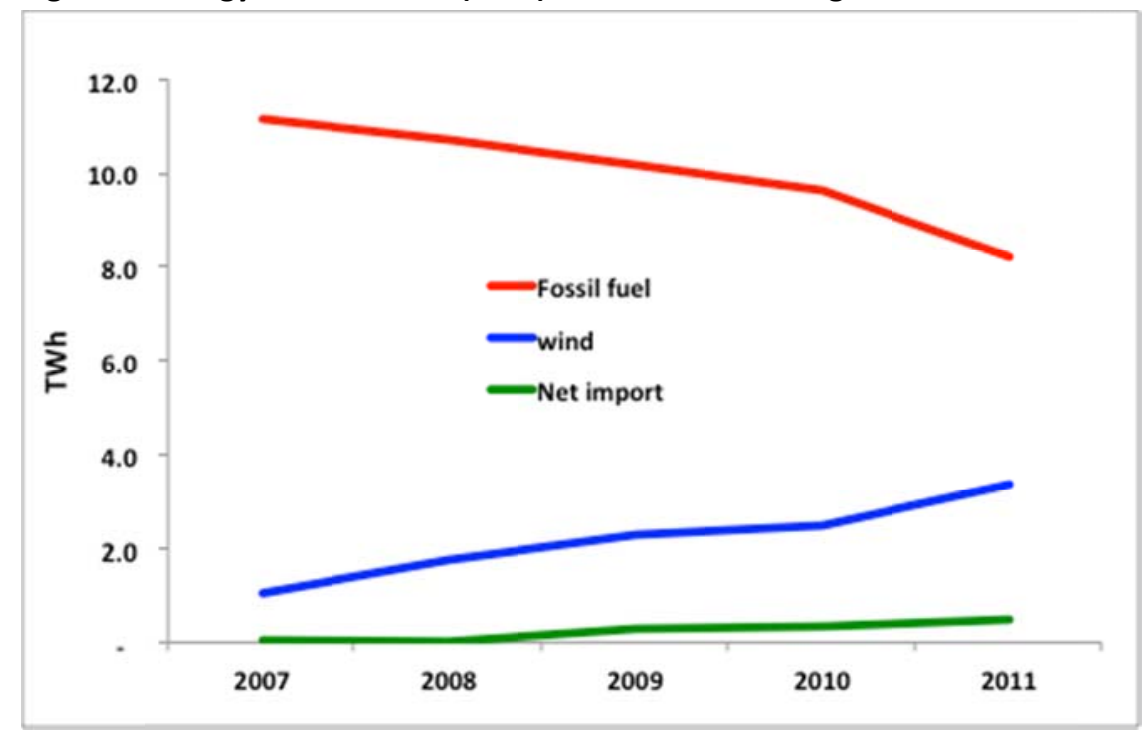

Since the stock of conventional fossil fuel plant has remained roughly constant over this period, declining electricity production from conventional plant is expressed in a decline in their aggregate average capacity factor from $50 \%$ in 2007 to $36 \%$ in 2011 .

Figure 5 below shows the share of energy produced during the 72 highest price half hour settlement periods in South Australia from 2005 to 2011. Wind generation has grown to reach a $9 \%$ share of electricity sold through the NEM in South Australia in these very high priced periods in 2011 (compared to a $26.7 \%$ share of the total electricity transacted through the NEM and produced in South Australia in 2011). Gas thermal, Combined Cycle Gas Turbines (CCGT) and brown coal generators have approximately a quarter share each while gas turbines (GT) and the interconnectors 
share the remaining $20 \%$ of the market. It is noticeable that market share has varied quite significantly particularly in respect of imports and production from gas thermal and (in 2011) the brown coal generators. We discuss the brown coal generation outcomes in more detail later.

Figure 5. Market share during the 72 highest price settlement periods

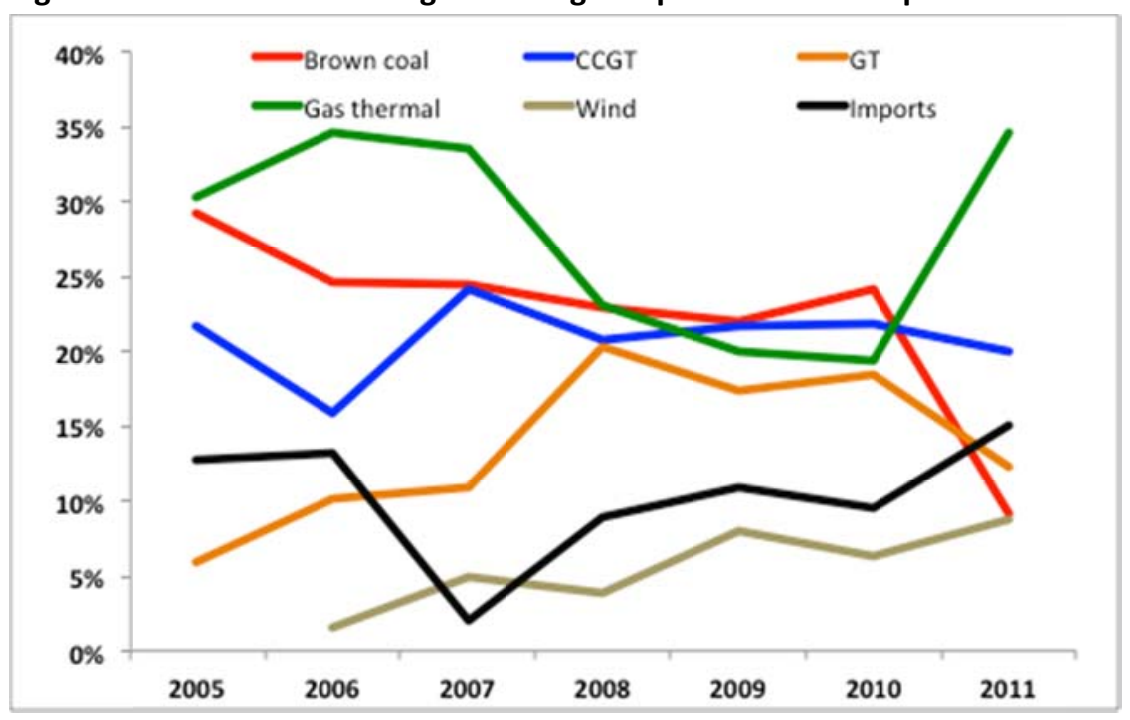

Figure 6 below shows that during the very high priced periods (which typically but not always occur at times of very high demand) wind production has been lower than its average annual production, and as a share of supply, very much lower than the annual averages. The average capacity factor of South Australian wind generation during the 72 highest price periods each year from 2007 to 2011 was $20 \%$, whereas their average annual capacity factor over this period has been $28 \%$.

Figure 6. Duration curves of demand and residual demand for the $\mathbf{7 2}$ highest price settlement periods in 2011

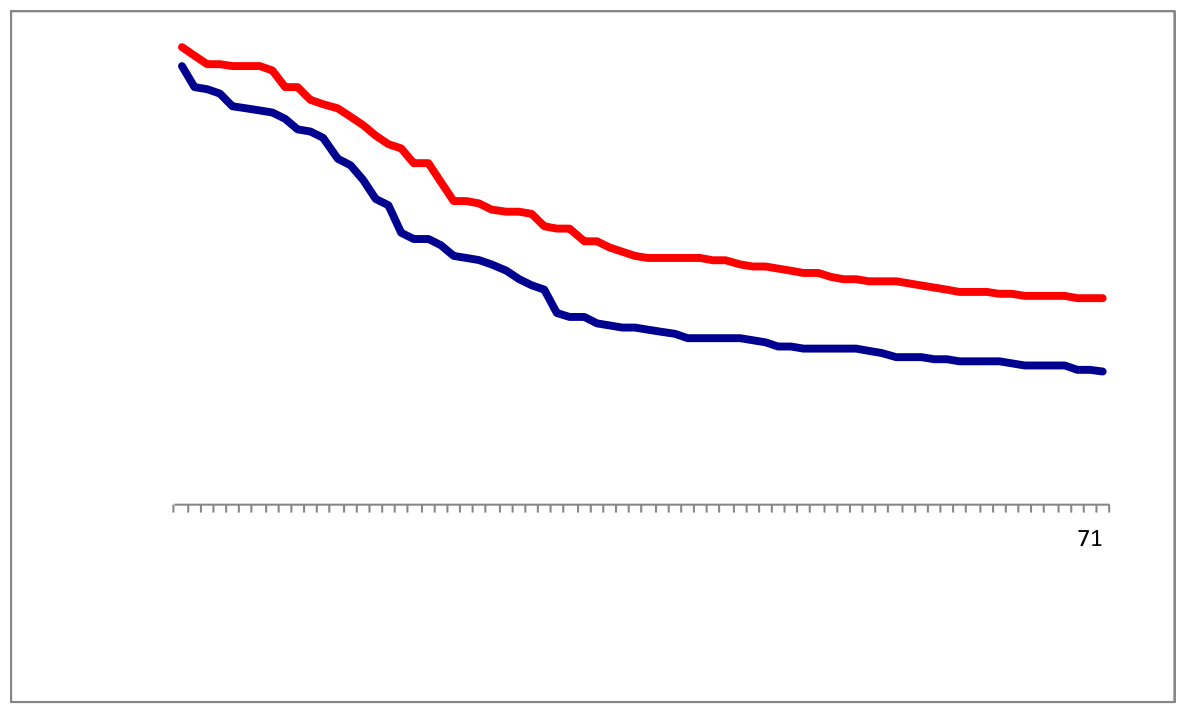

Cutler, Boerema et al. (2011) describe the climatological systems that give rise to the relatively lower wind generation at those times when temperatures (and hence electrical demand) is higher. 
Figure 7 explores the impact of the very high prices on the average prices achieved by wind farms between 2006 and 2011. It shows that if the very high prices are excluded, wind farms have received a relatively consistent discount, averaging around $\$ 6 / \mathrm{MWh}$ or $16 \%$ below the average annual price (excluding the top 72 settlement periods). By contrast, once the impact of the highest priced 72 settlement periods is included, wind farms have received substantially lower prices (up to $48 \%$ lower) than the supply-weighted average prices, particularly in 2008 and 2009 and to a lesser extent in 2010 and 2011.

Figure 7. The impact of the highest priced 72 settlement periods on the prices achieved by wind generators

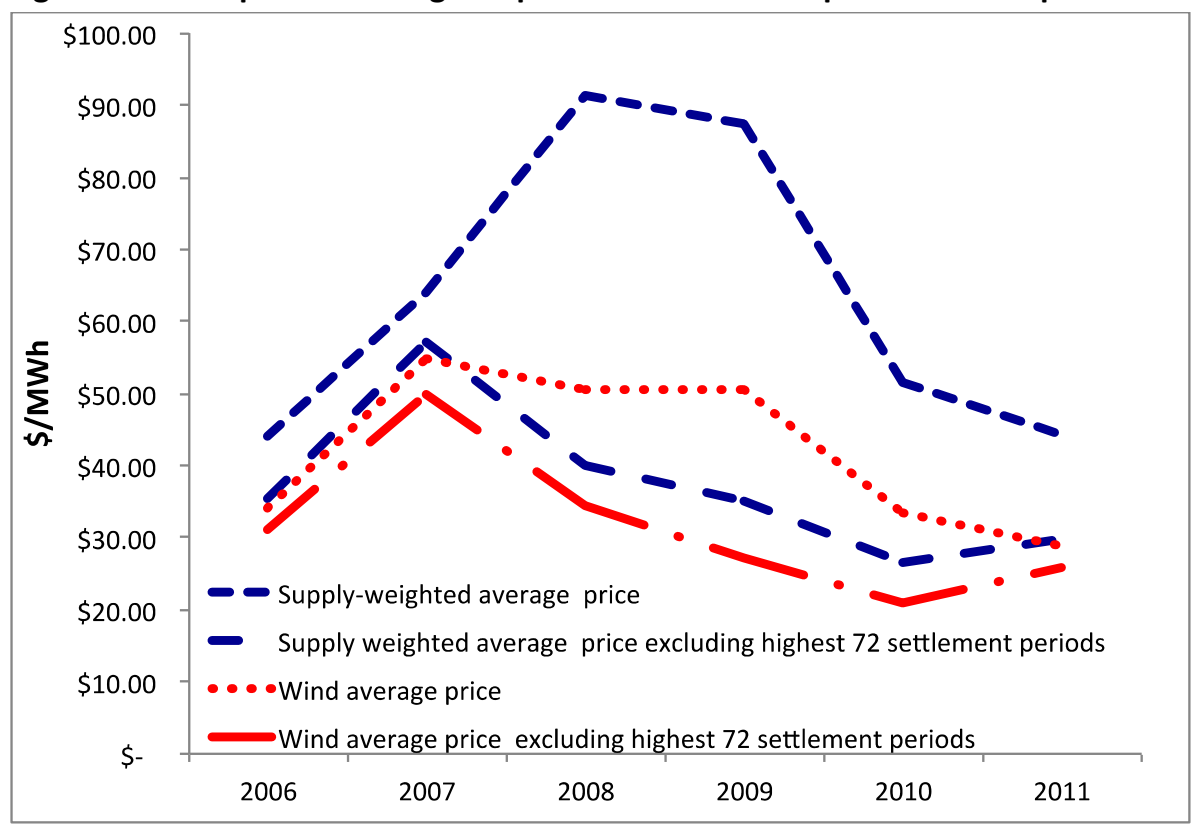

\section{Assessment}

\section{Evidence of the exercise of market power}

Across the economics literature there is a range of definitions of market power (Biggar 2011). In this paper, we will use the definition adopted in (Biggar 2011) that "a generator will be said to have market power if it can, by changing its output, affect the wholesale price that it is paid". With this definition, a test for the existence of market power (and the exercise of that power) would be whether spot prices substantially exceed the likely marginal costs of the highest cost dispatched generator, and at such times whether there are some dispatched generators that consistently produce substantially less electricity than they are capable of producing, and when exogenous factors do not inhibit production. Our methodology is consistent with that used by Joskow and Kahn (Joskow and Kahn 2002) in their analysis of market power in California's wholesale electricity market.

The capacity factor of a generator, as we use it in this analysis, is a measure of the average production of that generator as a ratio of its maximum possible production (based on its installed 
capacity). At any point in time, there might be many possible reasons why a gemerator might not be able to produce at its installed capacity including transmission congestion, outages or capacity reductions due to stochastic factors such as high temperatures and so on.

However, such factors (with the exception of enduring transmission congestion) can be expected only infrequently to limit the available capacity below the installed capacity of a generator. In a competitive market when spot prices are substantially above production costs, generators can be expected to seek to limit such adverse production factors so that they are able to maximise production and thereby maximise their gains from the high prices. Spot prices can rise far above marginal production costs, and be sustained at these high levels frequently. If such high prices reflect genuine scarcity, then there is no case that this reflects the exercise of market power.

However, if there is evidence that a generator consistently produces substantially below its capability when spot prices are substantially above that generator's production costs, then this is suggestive of the exercise of market power. If there is a big gap between prices and the production costs, and actual production is far below the possible production at these times, then this is likely to be especially significant.

The average capacity factor of generating plant, classified by technology (brown coal-fuelled generators, CCGT, GT, gas thermal generators and wind farms) in South Australia during the 72 highest price settlement periods for each year from 2007 to 2011 is presented in Figure 8.

Figure 8. Average capacity factors of different generation technologies during the highest 72 settlement periods

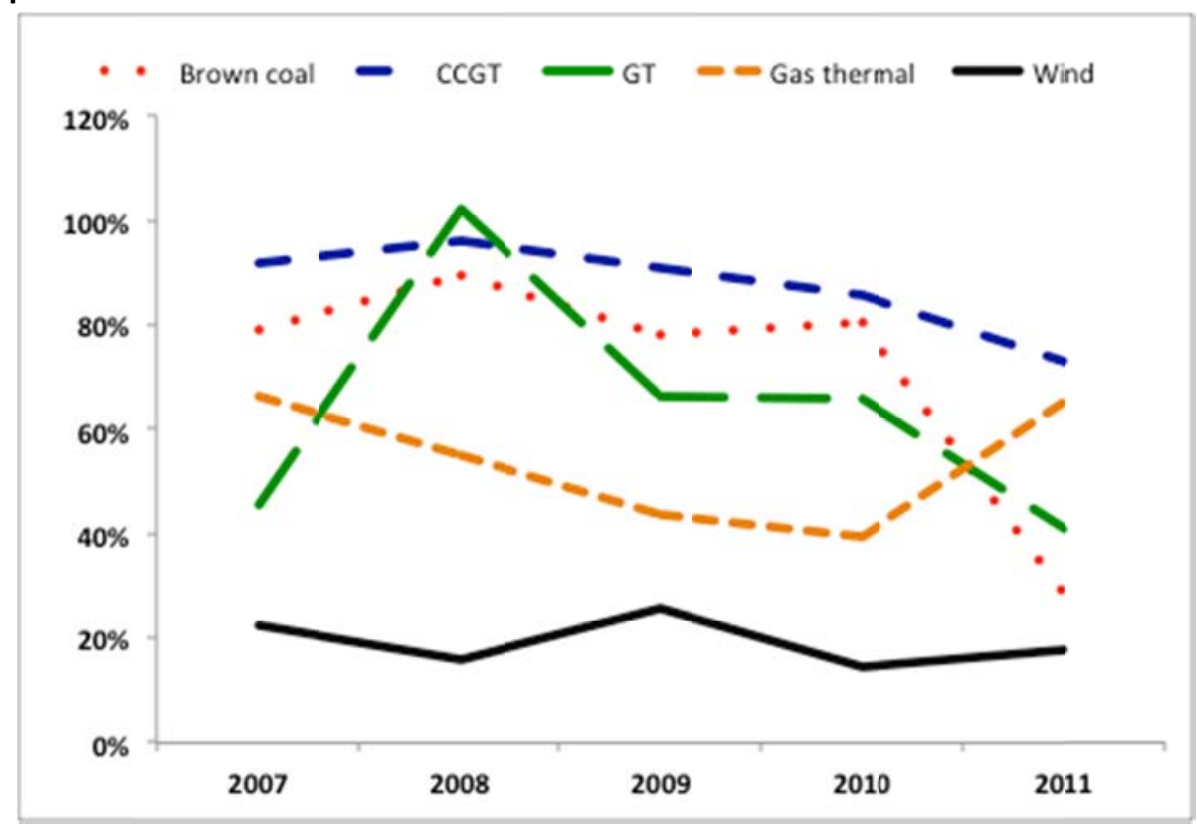

The figure shows that from 2008 to 2010 the $780 \mathrm{MW}$ of brown coal generation and $663 \mathrm{MW}$ of CCGT was operating on average during these highest price settlement periods at capacity factors above $80 \%$ and up to $98 \%$. Capacity factors of this level averaged over this period of time might reasonably be considered to reflect the generators' intention to maximise output during these high priced periods in these years. 
The performance of the gas thermal generator (the Torrens Island Power Station) in the three years from 2008 to 2010 is however notable for its low average annual capacity factors. In these three years, the average capacity factor for this power station in the highest priced 72 settlement periods in each year ranged between $42 \%$ and $57 \%$. In these settlement periods the spot price peaked at $\$ 10,000$ per MWh, averaged $\$ 6,034$ per MWh and was never less than $\$ 376$ per MWh. Torrens Island Power Station's variable production costs are not known with certainty, but they are unlikely to be above $\$ 60 / \mathrm{MWh}$. As such, to the extent that the Torrens Island Power Station was uncontracted it is likely that the exercise of market power would have produced very high marginal profits for the station's owners.

In other words, the Torrens Island Power Station only produced around half as much as it could, on average, in these settlement periods despite the fact that the spot price was never less than at least eight times higher than a reasonable estimate of the power station's variable production cost, and on average was around 130 times higher than its variable production costs. There were no enduring transmission constraints that affected its ability to produce and neither were there any other known enduring technical limitations that affected its availability at these times. As such the low average capacity factor of the Torrens Island Power Station reflects intentional dispatch outcomes, reflecting the prices at which the plant's owner made its production available in the market.

Such a large and sustained gap between production costs and spot prices points to the sustained exercise of market power by the Torrens Island Power Station over these years, the effect of which was to significantly raise spot market prices from what they otherwise would have been. Biggar and Hesamzadeh (2011) explains that Torrens Island Power Station's spot market sales were unhedged during this period and so it had an incentive to maximise prices in the spot market. ${ }^{1}$

In 2007 and 2011, the picture seems less clear. The capacity factor of Torrens Island in 2007 and 2011 (around 68\% for the highest priced 72 settlement periods in both years) is sufficiently high as to cast doubt on the conclusion that it clearly exercised market power in these years, or at least that the market power that it may have exercised in these years was consistent and significant. However the low capacity factor of the brown coal generators in 2011 (to just $30 \%$ on average in the top 72 settlement periods in 2011) when spot prices were many multiples higher than production costs is suggestive of the exercise of market power by these generators in that year. An examination of the data shows that the extreme prices in 2011, as in previous years, occurred for many consecutive settlement periods. This suggests that generator ramping constraints do not explain the extreme prices. In addition, we are not aware of mechanical failures or other exogenous events that explain the dispatch of the brown coal generators in the extreme price periods in 2011.

\footnotetext{
${ }^{1}$ A referee suggested that the appropriate test for market power should also take account of the probability of lost load, and so the relevant test for market power should account not just for production costs but also for the loss of load probability multiplied by the value of lost load. The probability of lost load can be assessed in various ways, but it is likely it to be small at the times that extraordinarily high prices occurred in South Australia over the periods that we have analysed. This is because during the very high priced periods there was a substantial gap between available capacity and demand (Mountain 2012).
} 


\section{Impact of the exercise of market power on the average spot prices received}

The combination of market share (on average over the year and during the 72 highest price periods) and highly volatile spot prices translates into significantly different average prices that different generating technologies in South Australia have achieved for their sales into the spot market, as shown in Figure 9.

Figure 9. Average prices achieved in the spot market for different generating technologies from 2008 to 2010

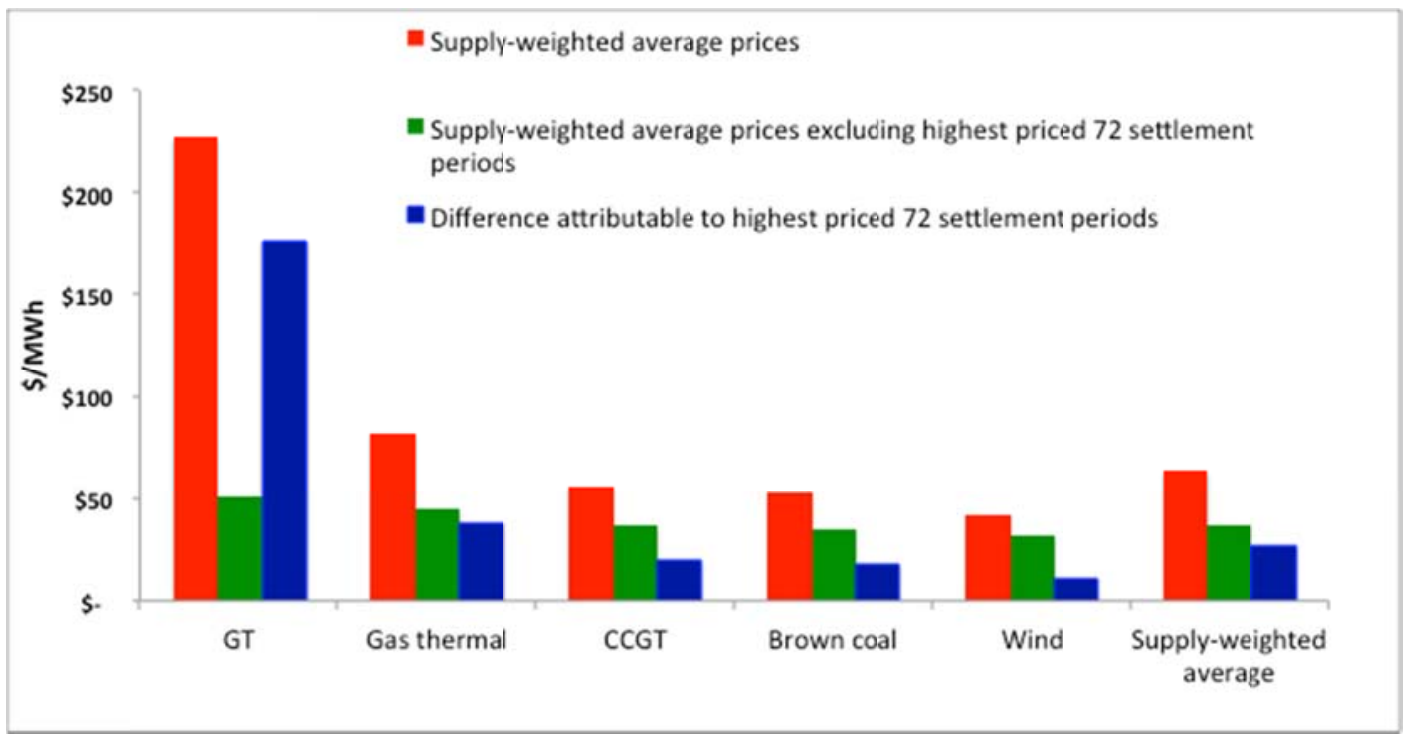

This figure shows gas turbines (GT) achieved the highest annual average supply-weighted prices as a result of high levels of production during the 72 highest price settlement periods. At the other extreme, wind generators achieved the lowest annual prices, and obtained the least benefit from the 72 highest price settlement periods. In particular, the impact of the 72 highest prices was to raise the average annual price received by wind farms by $64 \%$. By comparison the average annual prices for brown coal generators, CCGT, gas thermal and gas turbine were raised by $95 \%, 95 \%, 143 \%$ and $598 \%$ respectively.

As we noted earlier, Green and Vasilikos (2010) concluded that while wind generators gain less than conventional generators from the exercise of market power, the differential was expected to be only $15 \%$ for on-shore wind and $17 \%$ for off-shore wind. Our analysis of the situation in South Australia suggests a differential of $31 \%$ (for brown coal or CCGT plant relative to wind farms), $113 \%$ for gas thermal and $598 \%$ for OCGT.

\section{Impact of the exercise of market power on generator revenues and profits}

Extreme prices in a few settlement periods translates into spot market revenues that become extremely concentrated in these high price periods. This is illustrated in Figure 10. This shows the proportion of revenues recovered in the 72 highest price settlements periods in 2011 for different generator technologies. The figure shows in the 72 highest priced hours in the year, gas turbines (GT) had recovered around $90 \%$ of their revenues for that year. Gas thermal, brown coal and CCGT (not shown) recovered a little under half and wind generators around $33 \%$. Similar results are obtained for 2009 and 2008. 
Figure 10. Spot market revenue recovered in the 72 highest price settlement periods in 2011 as a percentage of total 2011 spot market revenue

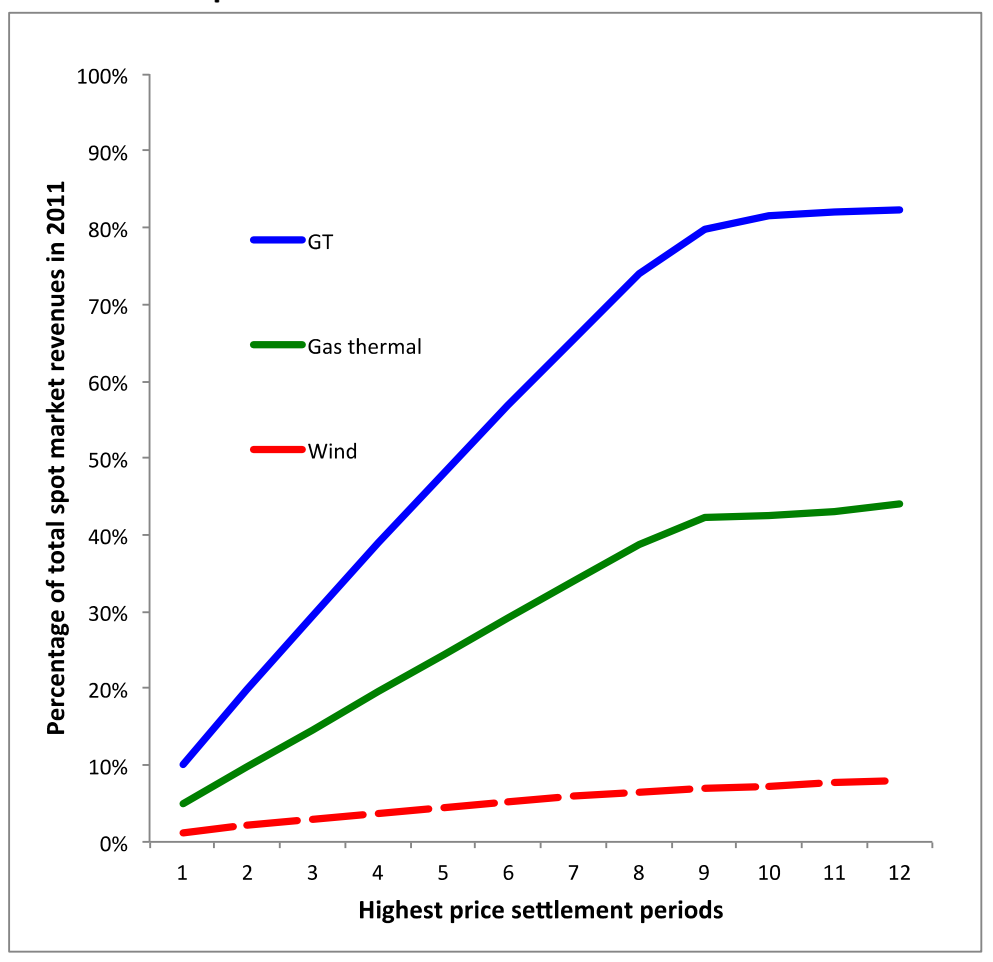

Extremely concentrated spot market revenues in the few extreme price periods will affect the profitability of generators - those that are able to maximise production during the extremely high priced periods will be relatively more profitable than those that produce evenly throughout the year. This differential in profitability will affect generation investment decisions.

To quantify this effect we have examined the relative profitability of investment in new entrant generation technologies: CCGT, OCGT and wind farms. The comparison we have drawn is of the profitability of investment in these generating technologies assuming that the average annual prices in 2008 pertained over the lives of the plant. This assessment of relative profitability is then compared to the relative profitability assuming that the extreme prices in the 72 highest settlement periods did not occur.

To estimate revenue over the life of plant we have assumed the new entrant generators would achieve the same capacity factors as the existing CCGT, GT and wind generators. To estimate the costs used in this calculation of profitability, we have assumed 25 year plant lives, zero residual values, that prices would remain unchanged in real terms over the 25 year plant life, a $10 \%$ cost of capital, that wind generators receive $\$ 40$ per Large Scale Generation Certificate (LGCs), and finally that capital and operating costs are as they are assumed to be by the Australian Government's Department of Resources Industry and Tourism (ACIL Tasman 2010)). No adjustment has been made to costs (or wholesale prices) to take account of the emission price to be implemented from 1 July 2012.

This outcome of this analysis is shown in Figure 11. Figure 11 shows the return on investment including and excluding the revenues derived the highest priced 72 settlement periods in 2008 . As 
expected, the profitability of both GT and CCGT is heavily impacted by revenues from the highest priced 72 settlement periods. For GT the impact is greater reflecting the fact that their high operating costs would mean that they would only compete for dispatch during the high priced settlement periods.

Figure 11. Return on investment for new entry CCGT, GT and wind farms based on outcomes in 2008, including and excluding revenues from the highest priced 72 settlement periods

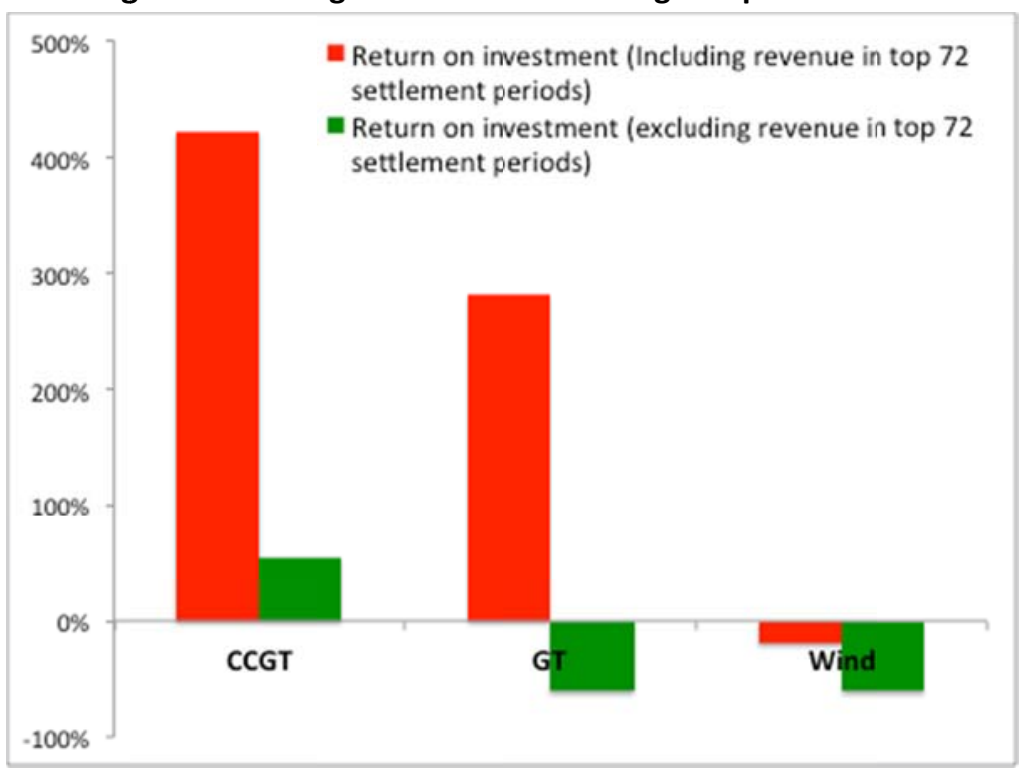

Comparable outcomes occurred in 2009 as in 2008 and the analysis using outcomes in 2009 delivers results that are similar to the results shown in Figure 11 for 2008. Even in 2011 when the brown coal generators rather than Torrens Island Power Station appear to have exercised market power (albeit apparently less successfully than Torrens Island) broadly confirms the observations shown in Figure 11 for 2008.

Figure 11 shows that wind farm profitability is significantly less affected by extremely high prices, delivering approximately the same negative return on investment regardless of the prices in the highest price 72 settlement periods. This reflects the relatively small impact of the highest prices on wind farms' annual spot market revenues (their production in the highest priced period is typically below their annual average production). In addition wind farms obtain around $50 \%$ of their income from the sale of LGCs, rather than the sale of electricity, thus further reducing the impact of electricity market outcomes on their profitability.

In summary, this analysis has concluded that the exercise of market power has rewarded conventional fossil fuel generators disproportionately more than wind farms. In the absence of the prices in the top 72 settlement periods, average spot prices would be too low to justify generation investment. Nonetheless wind farms would have been a relatively better (less unprofitable) investment than OCGT or CCGT. Including the prices in the top 72 settlements, investment in OCGT and CCGT becomes highly profitable, while investment in wind farms remains unprofitable although only slightly less than if prices in the top 72 settlements were included. So, whereas the profitability of investment in conventional generators appears to be highly sensitive to the exercise of market power, the exercise of market power makes little difference to the profitability of investment in wind farms. 


\section{Impact of wind farms on electricity prices in South Australia}

Research in other countries where wind generation is a significant proportion of the generation mix has concluded, generally, that wind generation has led or will lead to meaningful reductions in wholesale electricity prices at least in the short to medium term. For example:

- In a simulation of the German electricity market between 2001 and 2006 (Sensfus, Ragwitz et al. 2008) found that increasing wind generation had had an increasingly significant impact on wholesale prices, reducing them by between 2.5 and 7.8 Euros per MWh. Their conclusion was that in 2006 the subsidy provided to wind generators was more than compensated by wholesale market price reductions.

- In Ireland Mahoney and Denney (2011) used regression models to conclude that overall costs in the electricity market in Ireland would have been 12\% higher in 2009 if there was no wind generation.

- In Spain (de Miera, del Rio Gonzalez et al. 2008) simulated outcomes in the Spanish electricity market and from this analysis suggested that between 2005 and 2007 wind generators had delivered wholesale price reductions worth around Euro4.2bn.

In the longer term, the impact of the expansion of wind generation on prices seems less clear. Various studies conclude that higher variable cost peaking capacity will be needed as wind generation results in a steeper residual demand curve. See for example (Bushnell 2010) for a study of this in various electricity markets in the United States, (Moreno and Martiznez-Val 2011) in Spain, (Poyry Energy Consulting 2009) and (Green and Vasilakos 2010) in Britain and (Simshauser 2011) in Australia.

In South Australia, wind farms have taken market share from fossil fuel generators as shown in Figure 4. It can be expected that they have reduced average wholesale prices from what they otherwise would have been at times of lower system demand when the market is likely to be competitive and hence prices do not reflect scarcity or the exercise of market power. However, during the periods in which the market is competitive, the supply cost curve is likely to be relatively flat, and hence the effect of wind generation in reducing residual demand is likely to have resulted in relatively small price reductions at these times. Furthermore, as shown in Figure 8 , the supplyweighted average annual prices have been heavily affected by prices in the top 72 settlement periods. Thus even though wind generation may have reduced prices when the market is competitive (outside of the top 72 settlement periods), the effect of this on average annual prices will be diminished in view of the dominant impact of outcomes in the top 72 settlement periods on average annual prices.

Furthermore, we suggest that wind generation is likely to have had a limited impact on prices in the extreme price periods. It might be argued that wind generation has reduced the number of settlement periods in which market power might have been exercised, and hence in the absence of wind generation, the exercise of market power would have been even more severe and hence prices would have been even higher. This may be true to some extent, but average output from wind farms as a proportion of average demand in the highest price periods has not been very significant. For example in 2011, average wind generation as proportion of average demand in the highest priced 72 
settlement periods was 8.2\% (201 MW wind generation against 2,441 MW average demand), while average annual wind generation as a proportion of annual average demand was $23.8 \%$ (383 MW average annual wind generation against 1,609 MW average annual demand). Since wind generation has been a relatively small proportion of production during the peak price periods, it may not have had a significant impact in reducing the opportunity for the exercise of market power in these peak price periods.

For these reasons, the contribution of wind generation in reducing average annual prices is likely to be lower in South Australia, possibly significantly so, than it apparently has been in Spain, Germany and Ireland where wind generation is a similar proportion of the generation mix.

For these reasons, the contribution of wind generation in reducing average annual prices is likely to be lower in South Australia, possibly significantly so, than it apparently has been in Spain, Germany and Ireland where wind generation is a similar proportion of the generation mix.

\section{Conclusions and implications}

The analysis in this paper has shown that extremely high prices in a few settlement periods is beneficial to all generators but more so to conventional (fossil fuel) generators than it is to wind farms. This is understandable: unlike conventional generators, wind farms cannot increase production in response to higher market prices, their production is at the mercy of the prevailing winds. In South Australia extreme price periods often occur when temperatures are very high, and wind is lower than average. For this reason, wind farms in South Australia will generally receive lower average prices in the spot market than conventional generators. But if the market price - even at extreme price periods - reflects competitive outcomes, then it seems implausible to argue that the market is delivering a "bias" against investment in wind farms. In such cases, the differential in prices is reflecting the value of controllability of conventional generation compared to the intermittency of wind generation. So, where is the problem?

As we noted in the Introduction, Twomey and Neuhoff (2009) concluded that intermittent generation benefits less from market power than conventional generation and that allowing some level of market power as a means of encouraging investment in new generation may result in a bias against intermittent technologies. Green and Vasilakos (2010) agreed, but suggested that while wind generators gain less than conventional generators from the exercise of market power, the differential (15\% for on-shore wind and $17 \%$ for off-shore wind) was much less significant when compared to the impact of market power on wholesale prices (more than doubling them).

This paper has pointed to the exercise of market power, rather than genuine scarcity of generation capacity, as the reason for extreme prices in South Australia, particularly from 2008 to 2011. We concluded that whereas the profitability of investment in conventional generators appears to be highly sensitive to the exercise of market power, the exercise of market power has made little difference to the profitability of wind farms. We have therefore concluded, as have Twomey and Neuhoff, Green and Vasilakos, that the exercise of market power results in preference for investment in conventional generators, rather than in wind farms. 
Our analysis of outcomes in South Australia suggests that the effect is significantly larger than Green and Vasilakos modelled in Britain. There may be many reasons for this difference, amongst which is higher peak prices in South Australia attributable to the exercise of market power, than Green and Vasilakos expected in Great Britain. Prices in the NEM seem to have significantly higher peaks than in electricity markets in other countries.

Is this a problem worth worrying about? Answering this raises two subsidiary questions: firstly is the exercise of market power likely to be an enduring feature of the NEM and if so, does the resulting relative preference in favour of investment in fossil fuel plant, and against investment in intermittent generation, matter?

On the first question (is market power in the NEM an enduring feature) it is clear that the design of the NEM provides very powerful incentives for the exercise of market power. The NEM is an energyonly market with a very high price cap. The Australian Energy Markets Commission recently increased the cap from $\$ 10,000$ per MWh to $\$ 12,500$ per MWh, on the basis that a higher cap would stimulate investment and that this would reduce the likelihood of unmet demand. But if reducing availability is able to raise prices 200 fold or more, there is a very strong incentive to reduce availability. Raising the price cap strengthens the incentive to exercise market power by increasing the prices that may be achieved from capacity withholding or withdrawal.

The exercise of market power is not illegal under Australian competition law (the Consumer and Competition Act). The Act does not consider demand-side impacts (higher prices) - it is concerned primarily to ensure that the supply-side response to the exercise of market is not deterred. Specifically, Section 46 of the Act prohibits a business that has a substantial degree of market power from eliminating or substantially damaging a competitor, preventing entry into the market and deterring, or preventing a person from engaging in competitive conduct in any market.

While the Australian Energy Regulator has drawn attention to its concerns about the exercise of market power in the NEM, prosecutions for the exercise of such market power under Australian competition law have not been successful. Perhaps this reflects the difficulty of demonstrating that the exercise of market power in electricity markets will eliminate or substantially damage competitors, prevent entry or deter competitive conduct.

The combination of powerful incentives for the exercise of market power, and competition law that does not easily constrain such activity, at least in the energy market, is likely to mean that, absent policy change, the exercise of market power will be an enduring feature of the NEM. The outcomes in South Australia since 2007 provide some evidence of this. There seems to be general acceptance that the NEM is susceptible to the exercise of market power. For example the Chief Executive of Macquarie Generation in New South Wales, the largest generator in the NEM, has stated that his company has exercised market power in order to raise prices in the past, and can do so in future (Priest 2012).

Having established that the exercise of market power is relatively less advantageous to wind farms than fossil fuel generators, and that the exercise of market power is likely to be an enduring feature of the NEM, we can now turn to the last question: does this matter? We suggest it does because the Australian Government has set ambitious targets for the development of renewable electricity generation. Accelerating clean energy development is one of its four energy policy priorities 
(Department of Resources Energy and Tourism (Commonwealth of Australia) 2011). It therefore matters that the electricity market appears to be delivering outcomes that undermine this.

Assuming that wind farms meet $75 \%$ of the Government's renewable generation target (a conservative assumption taking account of the technological maturity and cost advantages of wind generation compared to other renewable generating technologies) additional wind generation capacity of around 8,000 MW will need to be installed in Australia over the next eight years. This will require capital outlays of around $\$ 24 \mathrm{bn}$. If the market is delivering a bias against investment in intermittent generators greater subsidy will be needed to compensate for this bias, than would be the case if the bias did not exist.

This means greater reliance on subsidies such as those provided through Large Scale Generation Certificates (LGCs) created under the Large Scale Renewable Energy Target. Greater dependence on subsidies that are separate from the electricity market will diminish the locational and temporal price signals provided by the electricity market for the useful output (electrical energy) that wind farms deliver. This is because LGC's are created - per MWh delivered - regardless of location or time of day. As the reliance on electricity market income reduces, so wind farms will be less sensitive to price signals provided in the electricity market to locate in those parts of the network that minimise transmission costs, or that maximise electricity production at the times most valued in the market. Diminished price signalling is conducive to lower investment efficiency.

In addition, wind farm investors are likely to discount future income from subsidies more heavily than they discount future income from the electricity market. This reflects lower investor confidence in the durability of Australia's renewables subsidy policy, relative to investor confidence in income derived from the sales of electricity in the electricity market. Australia's renewables policy has been subject to many significant changes over a short period of time. It remains a highly politicised area of Australia's energy policy. Absent changes to the market design, higher subsidies will be needed to compensate for this policy risk.

Bringing these observations together, we suggest that greater investment in wind farms could be delivered for lower total cost if wind farms were less reliant on subsidies and more reliant on income from the electricity market. Considering the size of the investment needed to meet the Australian Government's renewable energy targets there is likely to be significant economic benefit in ensuring that wind farms are appropriately remunerated through the electricity market rather than through highersubsidies.

How is this problem of market power and consequential bias against intermittent generation to be resolved? There are many possibilities. Changes to Australia's competition laws at least in their application to energy markets might increase the likelihood and success of prosecutions for the exercise of market power. The NEM could be redesigned or finessed in a number of ways including through the addition of capacity payments to reduce the reliance on compensation for energy produced, and hence reduce incentives to exercise market power. Alternatively, the market design might be left unchanged (an energy-only market) but price caps reduced to levels consistent with those in electricity markets in other countries. While changes need to be considered carefully and often-competing objectives need to be traded-off, this latter option is worthy of urgent examination. 


\section{Acknowledgements}

The author kindly acknowledges helpful comments from Ben Skinner, Peter Sheehan, Paul Simshauser, David Young, Mike Bagot, Darryl Biggar and two anonymous referees.

\section{References}

ACIL Tasman (2010). "Preparation of Energy Market Modelling Data for the Energy White Paper: Supply Assumptions Report". Canberra.

Australian Energy Market Operator (2011). "South Australian Supply and Demand Outlook". Melbourne.

Australian Energy Regulator (2009). "State of the Energy Market". Melbourne.

Australian Energy Regulator (2011). "State of the Energy Market". Melbourne.

Biggar, D. (2011). "The Theory and Practice of the Exercise of Market Power in the Australian NEM". Australian Competition and Consumer Commission, Melbourne.

Biggar, D. and M. Hesamzadeh (2011). "Modelling the hedging decisions of a generator with market power." Australian Energy Regulator, Melbourne.

Bushnell, J. (2010). "Building Blocks: Investment in Renewable and Non-Renewable Technologies". California, Energy Institute at Haas. El@ Haas WP 202, Berkeley.

Carstairs, J. and I. Pope (2011). "The case for a new capacity mechanism in the UK electricity market: Lessons from Australia and New Zealand"." Energy Policy 39: 5096-5098.

Climate Change Authority (2012). Renewable Energy Target Review: Final Report. Melbourne.

Cutler, N., N. Boerema, et al. (2011). "High penetration wind generation impacts on spot prices in the Australian national electricity market." Energy Policy 39: 5939-5949.

de Miera, S. G., P. del Rio Gonzalez, et al. (2008). "Analysing the impact of renewable electricity support schemes on power prices: The case of wind electricity in Spain." Energy Policy 36: 33453359.

Department of Resources Energy and Tourism (Commonwealth of Australia) (2011). "Draft Energy White Paper: Strengthening the Foundations for Australia's Energy Future." Canberra.

Energy Information Administration (2012). "Wholesale Market Data". US Energy Information Administration, Washington DC. At http://www.eia.gov/electricity/wholesale/ , accessed 29 February 2012.

Green, R. J. and N. Vasilakos (2010). "Market behaviour with large amounts of intermittent generation." Energy Policy 38(7): 3211-3320.

Joskow, P. L. and E. Kahn (2002). "A Quantitative Analysis of Pricing Behaviour in California's Wholesale Electricity Market." Energy Journal 23(4): 1-35. 
Mahoney, A. and E. Denny (2011). "The merit order effect of wind generation in the Irish electricity market." Department of Economics, Trinity College, Dublin.

Moreno, F. and J. M. Martiznez-Val (2011). "Collateral effects of renewable energies deployment in Spain: Impact on thermal power plants performance and management." Energy Policy 39. 39(10): 6561-6574.

Mountain, B. R. (2012). Electricity Market Power in South Australia: A Report for the Energy Users Association of Australia. Energy Users Association of Australia, Melbourne.

New Zealand Electricity Authority. (2012). "Wholesale market statistics". Wellington. At http://www.ea.govt.nz/industry/market/statistics-reports/wholesale-market-statistics/, accessed 29 February 2012.

Nicolisi, M. (2010). "Wind power integration and power system flexibility: An empirical analysis of extreme events in Germany under the new negative price regime." Energy Policy 38(11): 72577268.

Poyry Energy Consulting (2009). "Impact of Intermittency: How Wind Variability Could Change the Shape of the British and Irish Electricity Markets: Summary Report." Oxford. At http://www.uwig.org/ImpactofIntermittency.pdf , accessed 28 September 2012.

Priest, M. (2012). "Carbon tax hit threatens price blowout." Australian Financial Review. 29 February. Sydney.

Sensfus, F., M. Ragwitz, et al. (2008). "The merit-order effect: A detailed analysis of the price effect of renewable electricity generation on spot market prices in Germany." Energy Policy 36(8): 30863094.

Simshauser, P. (2011). "The hidden cost of wind generation in a thermal power system: What cost?" Australian Economic Review 44(3): 269-292.

Twomey, P. and K. Neuhoff (2009). "Wind power and market power in competitive markets." Energy Policy 38(7): 3198-3210. 